\title{
EVALUASI DESAIN TERMAL KONDENSOR PLTN TIPE PWR MENGGUNAKAN PROGRAM SHELL AND TUBE HEAT EXCHANGER DESIGN
}

\author{
Saut Mangihut Tua Naibaho"), Steven Darmawan ${ }^{1)}$ dan Suroso ${ }^{2)}$ \\ 1) Program Studi Teknik Mesin Universitas Tarumanagara, Jakarta \\ ${ }^{2)}$ Pusat Teknologi Reaktor Keselamatan Nuklir - BATAN \\ e-mail: suroso@batan.go.id
}

\begin{abstract}
The study was executed to get a quick calculation method for the design of equipment heat exchanger type shell and tube with a program shell and tube heat exchanger design. The purpose of this study was to obtain the results of the validation program shell and tube heat exchanger design of a condenser with power $4368.75 \mathrm{~kW}$ and the results of the evaluation program shell and tube heat exchanger design on the thermal design condensers nuclear power plant AP1000 PWR type. Input data into the program is done by inserting the parameters temperature, flow rate, physical properties and geometrical dimensions of the available designs of heat exchanger equipment specifications. Parameter for comparison of data can be obtained from the results of other calculations or experimental data. The results of comparison of the validation program shell and tube heat exchanger with condenser design calculations showed the highest difference found on $U_{\text {tube }}$ parameter equal to $1.3 \%$ lower than the design condition. This occurs because of differences in calculation between the program designed. The result evaluation of program shell and tube heat exchanger design toward the thermal design condensers nuclear power plant PWR type AP1000 obtained unknown parameters from the technical specifications.
\end{abstract}

Keywords: Validation and evaluation, heat exchanger type shell and tube, PWR AP1000, program shell and tube heat exchanger design.

\section{PENDAHULUAN}

Kebutuhan akan energi yang besar menuntut disediakannya sumber energi yang memadai namun dengan tingkat polusi rendah. Permasalahan tersebut dapat dijawab dengan penggunaan PLTN (Pembangkit Listrik Tenaga Nuklir) sebagai sumber energi, karena PLTN dapat menghasilkan energi yang besar namun dengan tingkat polusi rendah.

PLTN terdiri dari beberapa tipe, salah satunya adalah tipe PWR (Pressurized Water Reactor). PLTN tipe PWR merupakan pembangkit listrik yang menggunakan air sebagai pendingin reaktor. Sistem pendingin pada PWR terdiri dari tiga untai aliran pendingin yaitu untai primer, untai sekunder dan tersier. Pada untai primer, energi kalor dari reaktor dialirkan ke pembangkit uap kemudian oleh untai sekunder uap air dari pembangkit (steam generator) digunakan untuk menggerakkan turbin. Uap keluaran dari turbin dikondensasikan oleh alat kondensor menjadi air kondensat. Kondensor menggunakan air pendingin yang dialirkan pada untai tersier. PLTN tipe PWR pada umumnya menggunakan kondensor tipe permukaan (surface condenser), tipe kondensor ini merupakan jenis shell and tube di mana air pendingin disirkulasikan melalui tube, sementara uap panas dari turbin mengalir melalui sisi-shell kondensor.

Pada suatu instalasi PLTN kondensor merupakan komponen yang penting karena akan berpengaruh terhadap efisiensi turbin uap. Penggunaan kondensor yang tepat dapat meningkatkan kinerja PLTN secara keseluruhan. Penelitian dilakukan dengan mengevaluasi desain termal kondensor PLTN tipe PWR menggunakan program komputer. Program komputer yang digunakan untuk mengevaluasi desain adalah shell and tube heat exchanger design. Sebelum program digunakan untuk mengevaluasi kondensor dari PLTN tipe PWR, terlebih dahulu dilakukan validasi. dengan membandingkan hasil perhitungan program dengan perhitungan numerik yang telah dilakukan. Hasil validasi program shell and tube heat exchanger design akan memperoleh faktor koreksi. Faktor koreksi tersebut akan digunakan untuk mengevaluasi kondensor dari PLTN tipe PWR. Hasil validasi program shell and tube design dan evaluasi desain kondensor suatu PLTN tipe PWR yang diperoleh meliputi nilai pressure drop sisi shell dan sisi tube, koefisien perpindahan panas total, sisi shell dan juga sisi tube, serta dimensi dari kondensor itu sendiri. 


\section{METODOLOGI PENELITIAN}

Penelitian dilakukan menurut diagram alir Gambar 1. Validasi dilakukan terhadap kondensor dengan data spesifikasi teknis dan operasional sebuah kondensor yang diberikan pada Tabel 1.

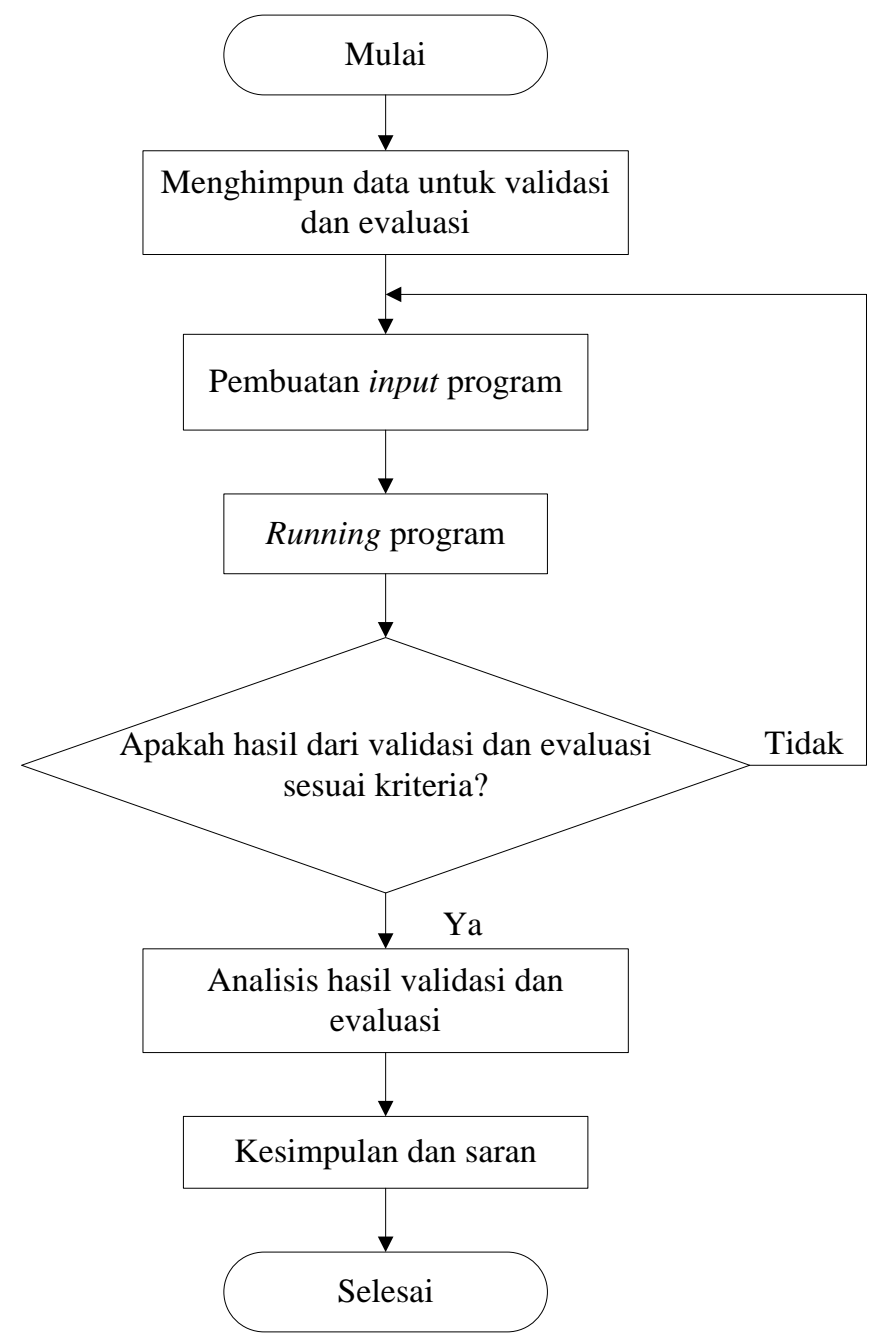

Gambar 1 Diagram alir penelitian.

Tabel 1. Data spesifikasi teknis dan operasional untuk validasi ${ }^{[6]}$

\begin{tabular}{clc}
\hline No. & \multicolumn{1}{c}{ Parameter } & Desain \\
\hline 1. & Daya $(\mathrm{kW})$ & $4.368,75$ \\
2. & Jumlah tube & 1.194 \\
3. & Shell/Tube pass & $1 / 4$ \\
4. & Pitch tube $(\mathrm{mm}) /$ /layout & $1,25 / \Delta$ \\
5. & Tube Diameter OD $(\mathrm{mm})$ & 20 \\
6. & Shell Diameter ID $(\mathrm{mm})$ & 1.130 \\
7. & Luas Permukaan $\left(\mathrm{m}^{2}\right)$ & 364 \\
8. & Panjang Tube $(\mathrm{m})$ & 4,88 \\
9. & DP sisi Shell $(\mathrm{kPa})$ & 1,322 \\
10. & P sisi Tube $(\mathrm{kPa})$ & 53,388 \\
\hline
\end{tabular}

Evaluasi desain kondensor dilakukan pada PLTN tipe PWR dengan data teknis yang terdapat pada Tabel 2. Software shell and tube heat exchanger design merupakan program yang 
digunakan untuk pengambilan data validasi maupun evaluasi. Pada Gambar 2 menunjukan tampilan depan dari program tersebut.

Tabel 2. Data spesifikasi teknis dan operasional kondensor PLTN tipe PWR.

\begin{tabular}{clc}
\hline No. & \multicolumn{1}{c}{ Parameter } & Desain \\
\hline 1. & Suhu Air Panas Masuk $\left({ }^{\circ} \mathrm{C}\right)$ & 50 \\
2. & Suhu Air Panas Keluar $\left({ }^{\circ} \mathrm{C}\right)$ & 40 \\
3. & Suhu Air Pendingin Masuk $\left({ }^{\circ} \mathrm{C}\right)$ & 26,7 \\
4. & Suhu Air Pendingin Keluar $\left({ }^{\circ} \mathrm{C}\right)$ & 30,5 \\
5. & Laju Aliran Panas $\left(\mathrm{m}^{3} / \mathrm{h}\right)$ & 51.755 \\
6. & Laju Aliran Dingin $\left(\mathrm{m}^{3} / \mathrm{h}\right)$ & 136.260 \\
7. & Shell / Tube Pass & $1 / 2$ \\
8. & Pitch Tube $(\mathrm{mm}) /$ Layout & $1,25 / \Delta$ \\
9. & Diameter Tube OD $(\mathrm{mm})$, BWG 20 & 22,22 \\
10. & Panjang Tube $(\mathrm{m})$ & 9,14 \\
\hline
\end{tabular}

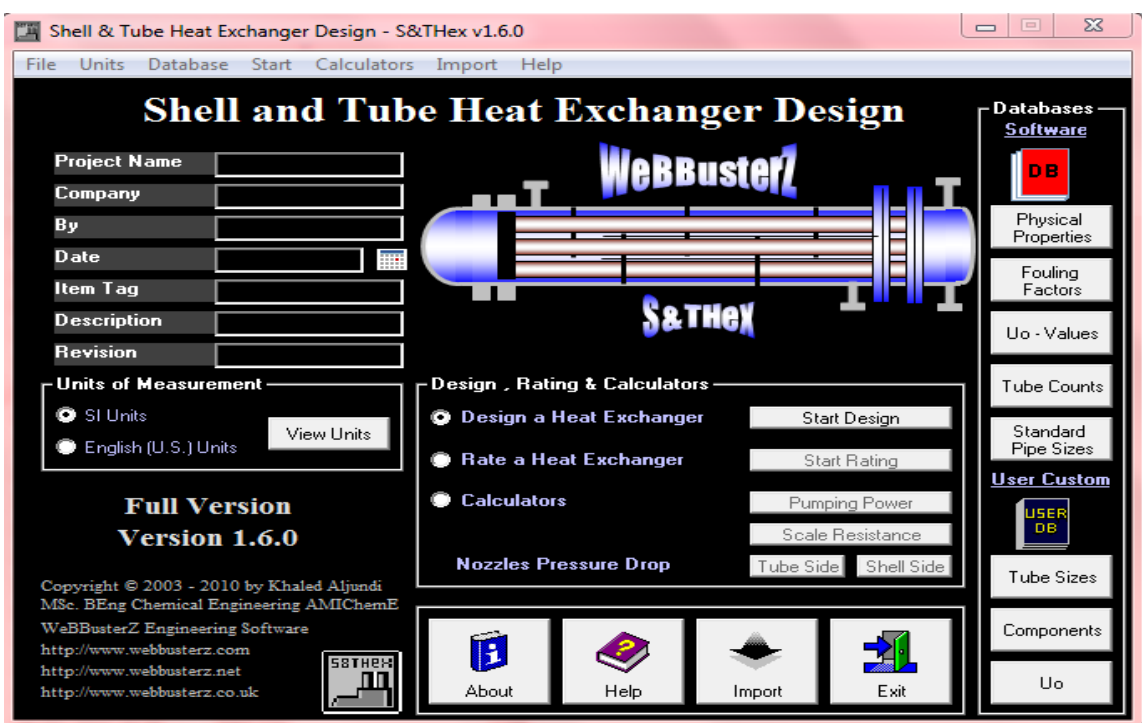

Gambar 2. Tampilan depan program shell and tube heat exchanger design [5].

Tahapan dalam pengimputan data ke program untuk mendapatkan hasil validasi maupun evaluasi terdiri dari 12 langkah. Gambar 3 dan 4 menunjukkan ke 12 langkah tersebut:

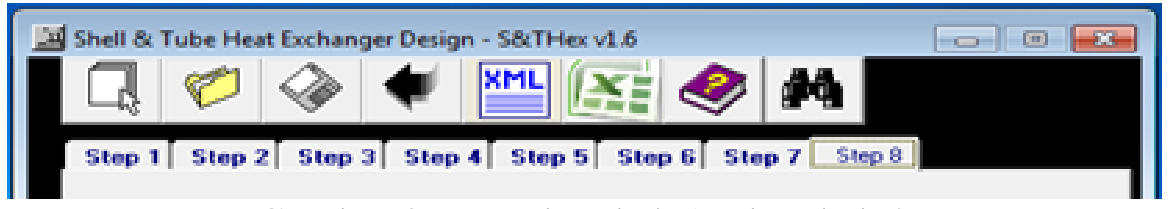

Gambar 3. Input langkah 1 - langkah 8

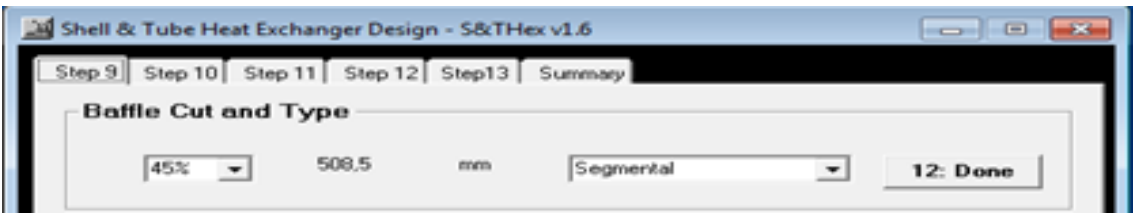

Gambar 4. Input langkah 9 - langkah 12.

Langkah 1 hingga 12 seperti yang ditunjukkan pada gambar 3 dan 4 pada perangkat lunak tersebut merepresentasikan parameter-parameter berikut secara berurutan; 
1) Parameter jenis fluida, temperatur sisi shell dan sisi tube, dan juga laju alir (flow rate).

2) sifat fisis pada sisi shell dan sisi tube.

3) Besar daya dari alat penukar kalor.

4) Parameterdimensi dari alat penukar kalor.

5) Perhitungan nilai LMTD (Log Mean Temperature Difference) dan True Temperature Difference.

6) Perhitungan nilai dari luas perpindahan panas (Heat Transfer Area) dengan mengklik “ 7Calculate “.

7) Jumlah tube (Number of Tube) alat penukar kalor dengan mengklik " 8-Calculate “.

8) Perhitungan bilangan Reynolds (Re), bilangan Prandtl (Pr), bilangan Nusselt (Nu), koedisien perpindahan kalor (hi) sisi tube, Baffle Spacing (jarak antar baffle), dan jumlah baffles.

9) Toleransi baffle (Baffle Cut) dan jenis baffle (Baffle Type), serta Typical Baffle Clerearance dan Baffle Tolerance.

10) Perhitungan Shell Side Heat Transfer Coefficient (koifisien perpindahan panas sisi shell).

11) Perhitungan Menghitung Overall Heat Transfer Coefficient (U).

12) Perhitungsn Pressure Drop $(\Delta \mathrm{P})$ pada sisi tube dan sisi shell.

\section{HASIL DAN PEMBAHASAN}

Validasi program shell and tube heat exchanger design dilakukan terhadap kondensor dengan daya 4.368,75 kW. Setelah mendapatkan hasil validasi, kemudian program shell and tube heat exchanger design digunakan untuk mengevaluasi desain termal kondensor pada PLTN AP1000. Hasil validasi dan evaluasi ditunjukkan pada Tabel 3 dan Tabel 4.

Tabel 3. Hasil validasi program shell and tube heat exchanger design terhadap kondensor dengan daya 4.368,75 kW.

\begin{tabular}{|c|c|c|c|c|}
\hline No. & Parameter & Desain & Hasil Desain & Penyimpangan (\%) \\
\hline 1. & Beban Kalor (kW) & $4.368,75$ & $4.368,75$ & - \\
\hline 2. & Suhu Air Panas Masuk $\left({ }^{\circ} \mathrm{C}\right)$ & 60 & 60 & - \\
\hline 3. & Suhu Air Panas Keluar $\left({ }^{\circ} \mathrm{C}\right)$ & 45 & 45 & - \\
\hline 4. & Suhu Air Pendingin Masuk $\left({ }^{\circ} \mathrm{C}\right)$ & 30 & 30 & - \\
\hline 5. & Suhu Air Pendingin Keluar $\left({ }^{\circ} \mathrm{C}\right)$ & 40 & 40 & - \\
\hline 6. & Laju Aliran Panas (kg/jam) & 45.000 & 45.000 & - \\
\hline 7. & Laju Aliran Dingin (kg/jam) & 376.200 & 376.200 & - \\
\hline 8. & Jumlah Tube per Pass & 298,5 & 298,5 & - \\
\hline 9. & Shell / Tube Pass & $1 / 4$ & $1 / 4$ & - \\
\hline 10. & Pitch Tube (mm) / Layout & $1,25 / \Delta$ & $1,25 / \Delta$ & - \\
\hline 11. & Diameter Tube OD (mm) & 20 & 20 & - \\
\hline 12. & Diameter Shell (mm) & 1.130 & 1.130 & - \\
\hline 13. & Jumlah baffle (45 \% ) & - & 5 & - \\
\hline 14. & Luas Permukaan $\left(\mathrm{m}^{2}\right)$ & 364 & 366,08 & 0,6 \\
\hline 15. & Panjang Tube (m) & 4,88 & 4,88 & - \\
\hline 16. & $\operatorname{LMTD}\left({ }^{\circ} \mathrm{C}\right)$ & 17,38 & 17,38 & - \\
\hline 17. & Fouling Factor & - & 0,000025 & - \\
\hline 18. & $\Delta \mathrm{P}$ sisi shell $(\mathrm{kPa})$ & 1,322 & 1,3235 & 0,11 \\
\hline 19. & $\Delta \mathrm{P}$ sisi tube $(\mathrm{kPa})$ & 53,388 & 53,388 & - \\
\hline 20. & $\mathrm{U}_{\text {overall }}\left(\mathrm{W} / \mathrm{m}^{2 \mathrm{o}} \mathrm{C}\right)$ & 1.049 & 1.049 & - \\
\hline 21. & $\mathrm{U}_{\text {Tube }}\left(\mathrm{W} / \mathrm{m}^{2}{ }^{\circ} \mathrm{C}\right)$ & 7.097 & $7.003,4$ & 1,3 \\
\hline 22. & $\mathrm{U}_{\text {Shell }}\left(\mathrm{W} / \mathrm{m}^{20} \mathrm{C}\right)$ & 1.447 & 1.443 & 0,28 \\
\hline 23. & Bilangan Reynold sisi tube & 44.208 & 44.200 & 0,02 \\
\hline 24. & Bilangan Reynold sisi shell & 121.235 & 121.000 & 0,19 \\
\hline
\end{tabular}


Tabel 3 menunjukkan perbandingan hasil perhitungan shell and tube heat exchanger design dengan menggunakan program dan dengan desain kondensor. Tipe kondensor ini adalah shell and tube dengan arah aliran berlawanan. Adapun spesifikasi kondensor tersebut adalah diameter shell $1.130 \mathrm{~mm}$, diameter tube $20 \mathrm{~mm}$ dan panjang tube 4,88 m. Jumlah tube sebanyak 1.194 buah dengan luas permukaan perpindahan panas $364 \mathrm{~m}^{2}$. Nilai koefisien perpindahan panas total 1.049 $\mathrm{W} / \mathrm{m}^{2}{ }^{\circ} \mathrm{C}$. Suhu masuk dan keluar sisi shell yaitu $60^{\circ} \mathrm{C}$ dan $45^{\circ} \mathrm{C}$ dengan laju aliran $45.000 \mathrm{~kg} / \mathrm{Jam}$. Sementara itu suhu masuk dan keluar sisi tube $32{ }^{\circ} \mathrm{C}$ dan $40{ }^{\circ} \mathrm{C}$ dengan laju aliaran 376.200 $\mathrm{kg} / \mathrm{Jam}$. Nilai pressure drop sisi shell 1,322 kPa dan sisi tube 53,388 kPa.

Tabel 4. Hasil evaluasi desain termal kondensor PLTN tipe AP1000

\begin{tabular}{clccc}
\hline No. & \multicolumn{1}{c}{ Parameter } & Desain & Desain Program & Penyimpangan (\%) \\
\hline 1. & Beban Kalor $(\mathrm{kW})$ & - & 597.774 & - \\
2. & Suhu Air Panas Masuk $\left({ }^{\circ} \mathrm{C}\right)$ & 50 & 50 & - \\
3. & Suhu Air Panas Keluar $\left({ }^{\circ} \mathrm{C}\right)$ & 40 & 50 & - \\
4. & Suhu Air Pendingin Masuk $\left({ }^{\circ} \mathrm{C}\right)$ & 26,7 & 26,7 & - \\
5. & Suhu Air Pendingin Keluar $\left({ }^{\circ} \mathrm{C}\right)$ & 30,5 & 30,5 & - \\
6. & Laju Aliran Panas $\left(\mathrm{m}^{3} / \mathrm{h}\right)$ & - & 51.755 & - \\
7. & Laju Aliran Dingin $\left(\mathrm{m}^{3} / \mathrm{h}\right)$ & 136.260 & 136.260 & - \\
8. & Jumlah Tube per Pass & - & $32.036,5$ & - \\
9. & Shell / Tube Pass & $1 / 2$ & $1 / 2$ & - \\
10. & Pitch Tube $(\mathrm{mm}) /$ Layout & $1,25 / \Delta$ & $1,25 / \Delta$ & - \\
11. & Diameter Tube OD $(\mathrm{mm})$ & 22,22 & 22,22 & - \\
12. & Diameter Shell $(\mathrm{mm})$ & - & 6.361 & - \\
13. & Jumlah baffle $(45 \%)$ & - & 2 & - \\
14. & Luas Permukaan $\left(\mathrm{m}^{2}\right)$ & - & $40.878,5$ & - \\
15. & Panjang Tube $(\mathrm{m})$ & 9,14 & 9,14 & - \\
16. & LMTD $\left({ }^{\circ} \mathrm{C}\right)$ & - & 16,2 & - \\
17. & Fouling Factor & - & 0,0003 & - \\
18. & DP sisi shell $(\mathrm{kPa})$ & - & 129,091 & - \\
19. & DP sisi tube $(\mathrm{kPa})$ & - & 162,414 & - \\
20. & $\mathrm{U}_{\text {overall }}\left(\mathrm{W} / \mathrm{m}^{20} \mathrm{C}\right)$ & - & 1.069 & - \\
21. & $\mathrm{U}_{\text {Tube }}\left(\mathrm{W} / \mathrm{m}^{20} \mathrm{C}\right)$ & - & 9.791 & - \\
22. & $\mathrm{U}_{\text {Shell }}\left(\mathrm{W} / \mathrm{m}^{20} \mathrm{C}\right)$ & - & 5.579 & - \\
23. & Bilangan Reynold sisi tube & - & 82.700 & - \\
24. & Bilangan Reynold sisi shell & - & 64.500 & - \\
\hline
\end{tabular}

Berdasarkan spesifikasi yang ada kemudian dilakukan validasi terhadap program shell and tube heat exchanger design. Hasil validasi yang dilakukan terhadap kondisi desain kondensor menunjukkan bahwa tidak terdapat perbedaan yang cukup signifikan. Perbedaan tertinggi hanya terjadi pada hasil perhitungan $\mathrm{U}_{\text {tube }}$ sebesar 1,3\%, dimana hasil perhitungan program lebih rendah dari kondisi desain. Hal ini dapat disebabkan oleh perbedaan cara perhitungan antara program dengan desain. Sementara itu untuk hasil perhitungan parameter yang lain tidak ada yang lebih dari 1\%, baik itu lebih tinggi ataupun lebih rendah dari kondisi desain. Hasil validasi ini menunjukkan bahwa perhitungan program shell and tube heat exchanger design cukup akurat sehingga layak digunakan untuk mengevaluasi desain termal kondensor PLTN tipe PWR AP1000.

Tabel 4 merupakan hasil evaluasi program shell and tube heat exchanger design terhadap desain termal kondensor PLTN tipe PWR AP1000. Hasil evaluasi desain program tidak dibandingkan terhadap desain kondensor dikarenakan keterbatasan data yang diperoleh dari spesifikasi teknis AP1000. Hanya beberapa parameter inputan saja yang diketahui sehingga dalam 
proses evaluasi ini hasil desain program digunakan untuk mengetahui parameter-parameter lain, seperti dimensi kondensor, koefisien perpindahan panas, pressure drop, dan lain-lain.

\section{Variasi Jumlah Baffle}

Di dalam perhitungan untuk memperoleh hasil validasi yaitu nilai koefisien perpindahan panas total $\left(\mathrm{U}_{\mathrm{o}}\right)$, koefisien perpindahan panas sisi shell, Reynold number sisi shell, dan pressure drop sisi shell sehingga memenuhi kriteria desain perhitungan maka dilakukan variasi pada jumlah baffle. Pengaruh dari perubahan jumlah baffle tersebut seperti pada Tabel 5 di bawah ini :

Tabel 5. Pengaruh variasi jumlah baffle

\begin{tabular}{ccccc}
\hline $\begin{array}{c}\text { Jumlah } \\
\text { Baffle }\end{array}$ & $\mathrm{U}_{\text {Overall }}\left(\mathrm{W} / \mathrm{m}^{20} \mathrm{C}\right)$ & $\mathrm{U}_{\text {shell }}\left(\mathrm{W} / \mathrm{m}^{20} \mathrm{C}\right)$ & $\begin{array}{c}\text { Reynold } \\
\text { Number }\left(\mathrm{x} 10^{3}\right)\end{array}$ & $\begin{array}{c}\Delta \mathrm{P}_{\text {Shell }} \\
(\mathrm{kPa})\end{array}$ \\
\hline 20 & $2.500,73$ & $7.178,11$ & 602 & 328,242 \\
\hline 15 & $2.159,15$ & $4.936,45$ & 414 & 106,159 \\
\hline 10 & $1.761,27$ & $3.255,2$ & 273 & 30,526 \\
\hline 5 & 1.049 & 1.443 & 121 & 1,324 \\
\hline
\end{tabular}

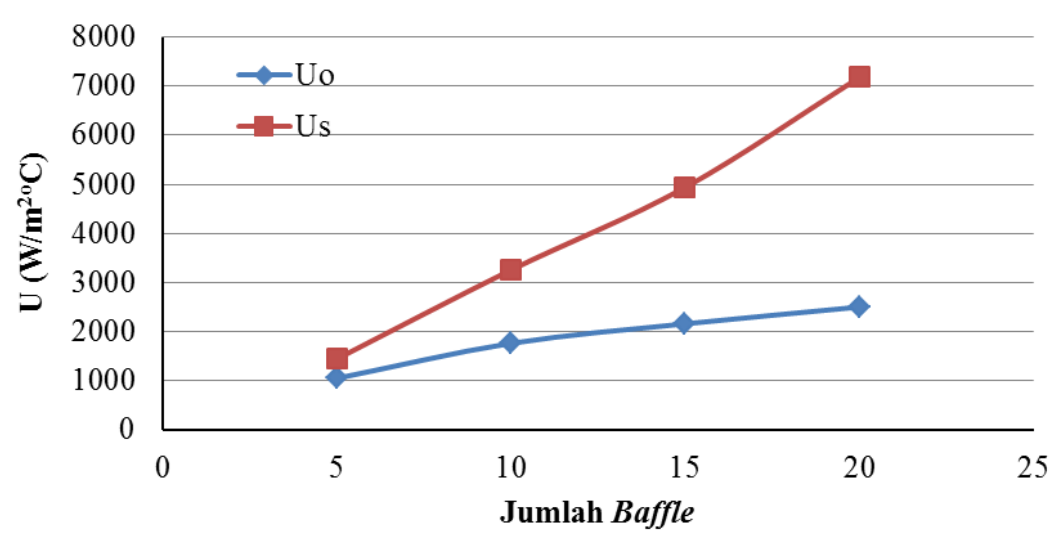

Gambar 5. Grafik koefisien perpindahan panas total (Uo) dan koefisien perpindahan panas sisi shell (Us) terhadap jumlah baffle.

Dari keempat grafik di atas dapat dilihat bahwa variasi jumlah baffle berbanding lurus dengan kenaikan setiap nilai setiap variabel, dimana semakin banyak jumalah baffle makin semakin tinggi pula nilai dari setiap variabel. Secara keseluruhan pengaruh variasi tersebut dapat dilihat pada Gambar 8 dimana terlihat bahwa variasi jumlah baffle paling berpengaruh terhadap nilai pressure drop sisi shell $\left(\Delta \mathrm{P}_{\text {Shell }}\right)$, hal ini dapat kita lihat dari interval kenaikan. Sementara untuk nilai variabel lain seperti koefisien perpindahan panas total (Uo), koefisien perpindahan panas sisi shell (Us), dan juga Reynold number sisi shell, interval kenaikan nilai masing-masing terhadap jumlah baffle tidak terlalu tinggi.

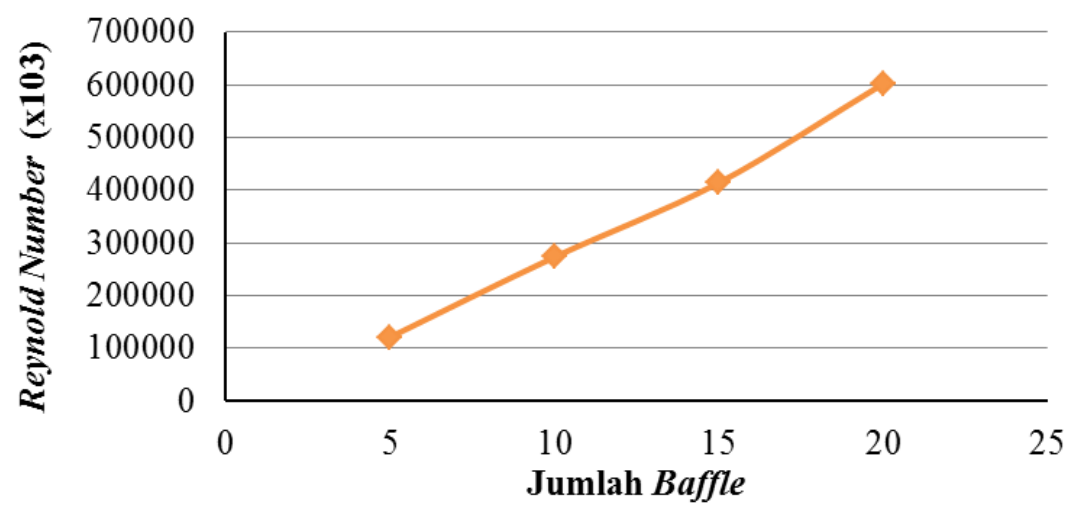

Gambar 6. Grafik Reynold number sisi shell terhadap jumlah baffle 


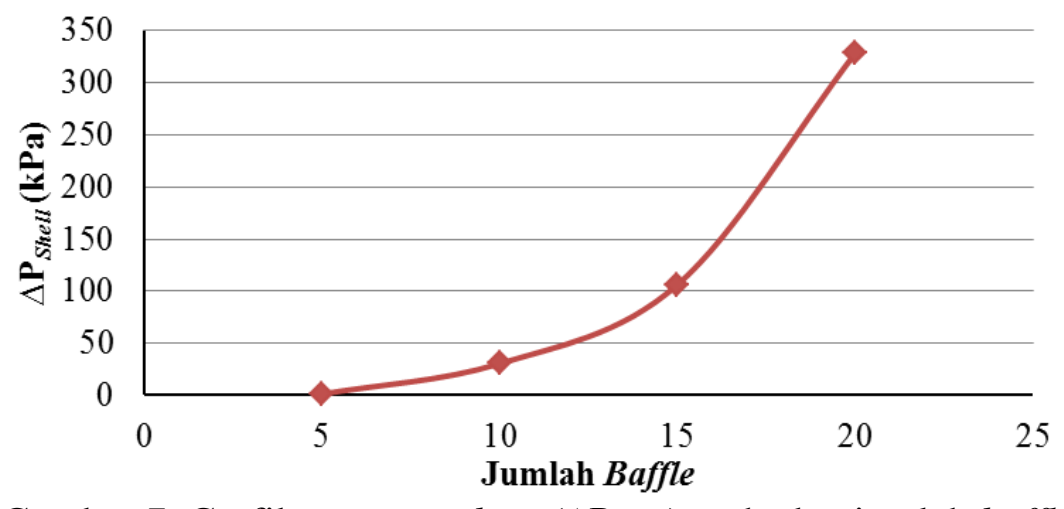

Gambar 7. Grafik pressure drop $\left(\Delta \mathrm{P}_{\text {Shell }}\right)$ terhadap jumlah baffle

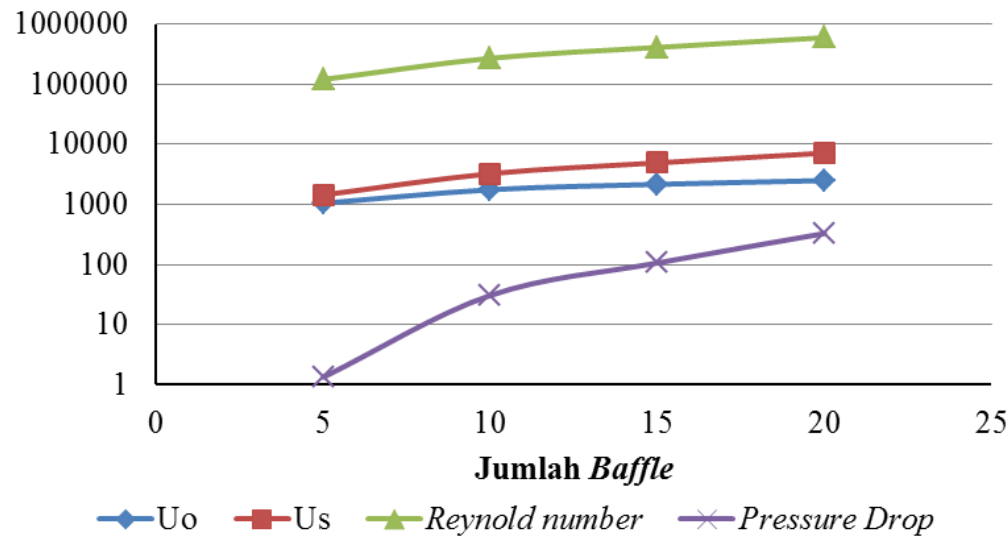

Gambar 8. Grafik antara jumlah baffle dengan koefisien perpindahan panas, Reynold number sisi shell, dan $\Delta \mathrm{P}_{\text {Shell. }}$

\section{KESIMPULAN}

Hasil validasi program shell and tube heat exchanger design terhadap kondensor berdaya 4.368,75 kW menunjukkan bahwa selisih tertinggi yang terjadi yakni pada nilai koifisien perpindahan panas sisi tube $\left(\mathrm{U}_{\text {tube }}\right)$ sebesar 1,3\% lebih rendah daripada kondisi desain. Hal ini diperkirakan terjadi karena adanya perbedaan cara perhitungan antara desain teknis dengan program shell and tube heat exchanger design. Namun untuk parameter lain seperti jumlah tube, panjang tube, luas permukaan perpindahan panas dan nilai pressure drop tidak terdapat perbedaan yang signifikan yakni kurang dari $1 \%$.

Sedangkan pada hasil evaluasi program shell and tube heat exchanger design terhadap kondensor PLTN tipe PWR AP1000 tidak terdapat perbedaan yang cukup signifikan. Sementara dikarenakan keterbatasan informasi mengenai karakteristik yang lain tentang kondensor AP1000 dimana hal ini merupakan rahasia dari perusahan, tetapi hasil perhitungan validasi yang cukup meyakinkan menjadikan perhitungan ini telah sesuai dan mendapatkan hasil yang baik.

Jumlah baffle sangat mempengaruhi nilai dari koefisien perpindahan panas total, koefisien perpindahan panas sisi shell, Reynold number sisi shell, dan juga pressure drop sisi shell. Semakin banyak jumalah baffle maka semakin tinggi pula nilai dari setiap variabel tersebut.

\section{DAFTAR PUSTAKA}

[1] Dibyo, Sukmanto. Perhitungan Desain Termal Kondensor Pada Sistem Pendingin PWR. Epsilon. PTRKN-BATAN, November 2009.

[2] Holman, JP., dan Jasfi, Penukar Kalor. Jakarta : Penerbit Erlangga, 1994

[3] Kreith, Frank, Prijino, Arko. Prinsip-Prinsip Perpindahan Panas. Edisi ketiga. Jakarta :Penerbit Erlangga, 1995.

[4] Cengel, A. Yunus. INTRODUCTION TO THERMODYNAMICS AND HEAT TRANSFER, 
Second Edition. Mc Graw Hill.2008.

[5] Aljundi, Khaled. Webbusterz Engineering Software. United States Of America, 2010.

[6] Coulson., AND Ricardson's. Chemical Engineering Design, Volume 6. R.K Sinnott, 2005.

[7] Massoud, M. Engineering Thermofluids.Germany : Springer, 2005

[8] Whiteman, JL. AP1000 European Design Control Document Revision 1. Pittsburgh: Westinghouse, 2009.

[9] Wu.E. Cummins, M.M. Corletti, T.L. Schulz. 2003. Westinghouse AP1000 Advanced Passive Plant. Spain: Westinghouse Electric Company, LLC.

[10] Morris, M. Mechanical Design of Heat Exchangers. Tersedia http://www.thermopedia.com/content/946/. (5 Mei 2012).

[11] Brogan, R.J. Shell and Tube Heat Exchanger. http://www.thermopedia.com/content/1121/. (5 Mei 2012). 